\title{
Comparison of the Inhibitory Effects of Docosahexaenoic Acid (DHA) on U46619- and Phenylephrine-Induced Contractions in Guinea-Pig Aorta
}

\author{
Kazuoki Otsuka, ${ }^{a}$ Yoshio TanaKa, ${ }^{*, b}$ Hikaru Tanaka, ${ }^{a}$ Katsuo KoIKe, ${ }^{b}$ and Koki Shigenobu ${ }^{a}$ \\ ${ }^{a}$ Department of Pharmacology, Toho University School of Pharmaceutical Sciences; and ${ }^{b}$ Department of Chemical \\ Pharmacology, Toho University School of Pharmaceutical Sciences; 2-2-1 Miyama, Funabashi, Chiba 274-8510, Japan. \\ Received November 8, 2004; accepted April 5, 2005
}

\begin{abstract}
Inhibitory effects of docosahexaenoic acid (DHA) on the muscle contractions induced by U46619, a thromboxane $\mathrm{A}_{2}\left(\mathrm{TXA}_{2}\right)$ mimetic, and phenylephrine were compared in guinea-pig aorta. In de-endothelialized guineapig aortic ring preparations, DHA at $10 \mu_{\mathrm{M}}$ strongly inhibited a sustained contraction produced by U46619 (3-100 nM) whereas it did not exhibit an appreciable effect on phenylephrine $(3-10 \mu \mathrm{M})$-induced contraction. The present findings indicate that $\mathrm{DHA}$ inhibits more selectively $\mathrm{TXA}$ receptor (TP receptor)-mediated vascular contraction than $\alpha$-adrenoceptor-mediated response. Selective inhibition by DHA of TP receptor-mediated contraction of blood vessels seems underlie in part the mechanisms by which this polyunsaturated fatty acid exerts its circulatory-protective effects.
\end{abstract}

Key words docosahexaenoic acid (DHA); thromboxane $\mathrm{A}_{2}\left(\mathrm{TXA}_{2}\right)$; vascular smooth muscle; thromboxane $\mathrm{A}_{2}$ receptor (TP receptor); $\alpha$-adrenoceptor; guinea-pig aorta

Docosahexaenoic acid (DHA) is an n-3 type of polyunsaturated fatty acid ( $\omega-3$ fatty acid). This fatty acid is richly contained as well as eicosapentaenoic acid (EPA) in the fish oil. DHA has been shown to prevent the incidence of cerebral thrombosis, cardiac infarction, arrhythmia, atherosclerosis and hypertension and others. ${ }^{1,2)}$ These circulatory-protective effects of DHA could be partly ascribed to vascular relaxation attained with this fatty acid. In support of this presumption, DHA produces relaxation in the isolated vascular tissue. ${ }^{3-7)}$ However, in these studies, relaxant effects of DHA were mainly examined against the contractions elicited by $\alpha$-adrenoceptor stimulation with phenylephrine or norepinephrine or by depolarizing high- $\mathrm{KCl}$ solution. Furthermore, more than $100 \mu \mathrm{m}$ of DHA seems to be required to produce a potent vascular relaxation. In the present study, we show that DHA diminishes more strongly thromboxane $\mathrm{A}_{2}\left(\mathrm{TXA}_{2}\right)$ receptor (TP receptor)-mediated contraction with less concentration $(10 \mu \mathrm{M})$ than that elicited through $\alpha$-adrenoceptor in guinea-pig aorta. This novel action of DHA to inhibit more selectively TP receptor-mediated vasocontraction could substantially contribute to the suppressive effects of this fatty acid on the occurrence of vasospasm.

\section{MATERIAL AND METHODS}

Hartley guinea-pigs of either sex were housed under controlled conditions (temperature $21-22^{\circ} \mathrm{C}$, relative air humidity $50 \pm 5 \%$ ). Food and water were available ad libitum to all animals. This study was conducted in accordance with the Guideline for the Care and Use of Laboratory Animals adopted by the Committee on the Care and Use of Laboratory Animals of Toho University School of Pharmaceutical Sciences (accredited by the Ministry of Education, Culture, Sports, Science, and Technology (MEXT), Japan).

Preparation of Thoracic Aortic Rings and Measurement of Tension Changes Preparation of thoracic aortic rings and tension change measurements followed our previous procedures. ${ }^{899}$ Briefly, a section of the thoracic aorta was removed from guinea-pigs and placed in normal Tyrode's solution (mM): $\mathrm{NaCl}, 158.3 ; \mathrm{KCl}, 4.0 ; \mathrm{CaCl}_{2}, 2.0 ; \mathrm{MgCl}_{2}$,
1.05; $\mathrm{NaH}_{2} \mathrm{PO}_{4}, 0.42 ; \mathrm{NaHCO}_{3}, 10.0$ and glucose, 5.6. The aorta was cleaned of loosely adhering fat and connective tissues, and cut into ring segments of about $2 \mathrm{~mm}$ in length. The endothelium was removed by rubbing gently the intimal surface of ring preparations with a manicure painting brush. Subsequently, the ring segments were mounted using stainless steel hooks (outer diameter, $200 \mu \mathrm{m}$ ) under the optimal resting tension of $1.0 \mathrm{~g}$ in a $5-\mathrm{ml}$ organ bath (UC-5; UFER Medical Instrument, Kyoto, Japan) containing normal Tyrode's solution. Muscle tension changes were isometrically recorded with a force-displacement transducer (TB-611T: Nihon Kohden, Tokyo, Japan) connected to a minipolygraph (RM-6100; Nihon Kohden, Tokyo, Japan). Ring preparations were equilibrated for $60-90 \mathrm{~min}$ prior contraction with isotonic high- $\mathrm{KCl}(80 \mathrm{~mm})$ Tyrode's solution $(\mathrm{mm}): \mathrm{NaCl}$, 82.3; KCl, 80.0; $\mathrm{CaCl}_{2}, 2.0 ; \mathrm{MgCl}_{2}, 1.05 ; \mathrm{NaH}_{2} \mathrm{PO}_{4}, 0.42$; $\mathrm{NaHCO}_{3}, 10.0$ and glucose, 5.6. After washing out, the absence of endothelial cells was confirmed by the lack of relaxation induced by acetylcholine $\left(\mathrm{ACh} ; 10^{-5} \mathrm{M}\right)$, and experiments were started after a 30-min equilibration period. Normal Tyrode's solution was continuously gassed with $95 \% \mathrm{O}_{2}-5 \% \mathrm{CO}_{2}$, and kept at $36.5 \pm 0.5^{\circ} \mathrm{C}(\mathrm{pH}=7.35)$.

Evaluation of Inhibitory Effects of Docosahexaenoic Acid (DHA) on the Contractions Induced by U46619 and Phenylephrine Aorta was precontracted with U46619 (3$100 \mathrm{~nm})$ or phenylephrine $(3,10 \mu \mathrm{M})$. After the muscle contractions reached a steady-state level, DHA $(10 \mu \mathrm{M})$ was applied to the bath medium. Inhibitory effects of DHA were evaluated at steady-state. To obtain the concentration-dependency for the inhibitory effects of DHA, this polyunsaturated fatty acid $(1-30 \mu \mathrm{M})$ was tested against the contraction induced by $10 \mathrm{~nm}$ U46619. At the end of experiment, papaverine $(100 \mu \mathrm{M})$ was applied to obtain the substantially maximal inhibitory response. Muscle tensions before and after application of DHA/papaverine were expressed as percent relaxation by considering the tension level just before addition of DHA as $0 \%$ relaxation, and the basal tension level before application of U46619 or phenylephrine as $100 \%$ relaxation.

Drugs Drugs used in the present study were: docosa- 
hexaenoic acid (DHA), 9,11-dideoxy-9 $\alpha, 11 \alpha$-methanoepoxy prostaglandin $\mathrm{F}_{2 \alpha}$ (U46619) (Cayman Chemical, Ann Arbor, M.I., U.S.A.); L-phenylephrine hydrochloride (Sigma-Aldrich Co., St. Louis, M.O., U.S.A.), papaverine hydrochloride (Wako Pure Chemical Industries, Osaka, Japan). All other reagents used were commercially available and of reagent grade. DHA was dissolved in pure ethanol as a stock solution at $10 \mathrm{~mm}$. U46619 was dissolved in $70 \%$ ethanol as a stock solution at $100 \mu \mathrm{M}$. Final ethanol concentration in the bath medium did not exceed $0.1 \%$.

Statistics Data are presented as means \pm S.E.M. and $n$ refers to the number of experiments. The significance of the difference between mean values was evaluated by paired $t$-test using GraphPad Prism ${ }^{\mathrm{TM}}$ (version 3.02; GraphPad Software, San Diego, Calif., U.S.A.). A $p$-value less than 0.05 was considered statistically significant.

\section{RESULTS AND DISCUSSION}

Figure 1 shows the inhibitory effects of DHA on the sustained contractions induced by U46619 and that by phenylephrine in de-endothelialized guinea-pig aorta. DHA at $10 \mu \mathrm{M}$ strongly suppressed U46619 (10 nM)-induced contraction (Fig. 1A) whereas it did not exhibit an appreciable effect on the contraction induced by phenylephrine $(10 \mu \mathrm{M})$ (Fig. 1B). In both cases, its vehicle (pure ethanol) did not affect the sustained contractions induced by U46619 and phenylephrine (data not shown). Figure 2 summarizes the inhibitory effects of DHA $(10 \mu \mathrm{M})$ on the contractions induced by U46619 (Fig. 2A) and phenylephrine (Fig. 2B). DHA $(10 \mu \mathrm{M})$ significantly inhibited sustained contractions induced by U46619 at concentrations from 3 to $100 \mathrm{~nm}$ though its inhibitory effect was reduced when the blood vessel was contracted with higher concentrations of U46619 (Fig. 2Aa). On the other hand, DHA $(10 \mu \mathrm{M})$ did not significantly attenuate the muscle tension increased by phenylephrine at both $3 \mu \mathrm{M}$ and $10 \mu \mathrm{M}$ (Fig. 2Ba). The degree of muscle tension level can be ruled out to account for the incapability of DHA to diminish phenylephrine-induced contraction since the contraction induced by phenylephrine was less than that induced by U46619 (Figs. 2Ab, 2Bb); for instance, $10 \mu \mathrm{M}$ phenylephrine-induced contraction was $76 \%$ of the tension development induced by high- $\mathrm{KCl}(80 \mathrm{~mm})$ (Fig. 2Bb) whereas $10 \mathrm{~nm}$ U46619-induced contraction was $96 \%$ of high-KCl-induced tension (Fig. 2Ab).

Figure 3 shows the concentration-dependent effects of DHA on the contraction induced by U46619 (10 nM). DHA in the concentrations from 1 to $30 \mu \mathrm{m}$ significantly inhibited U46619-induced contraction, which was found to be concentration-dependent. In this condition, $\mathrm{IC}_{50}$ value of DHA was calculated to be $5.6 \pm 0.6 \mu \mathrm{M}(n=6)$.

The present study clearly shows that DHA more selectively diminishes $\mathrm{TXA}_{2}$ receptor (TP receptor)-mediated contraction than the response mediated through $\alpha$-adrenoceptor in the conduit artery of guinea-pig. One plausible explanation for the present finding is that DHA directly antagonizes the $\mathrm{TXA}_{2}$ mimetic at TP receptor to counteract its vascular

A

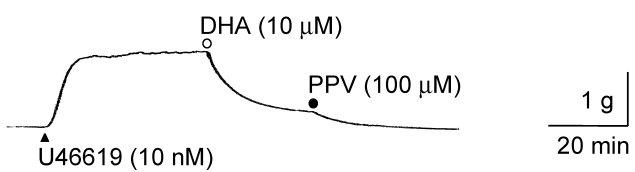

B

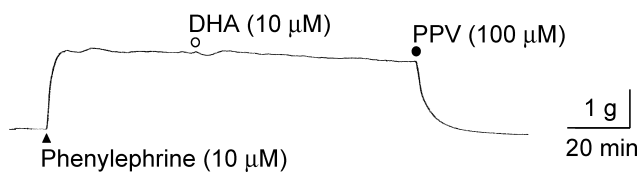

Fig. 1. Typical Mechanical Traces Showing the Relaxant Effects of DHA $(10 \mu \mathrm{M})$ on the Sustained Contractions Induced by U46619 (a TXA Mimetic, $10 \mathrm{~nm}$ ) (A) or by Phenylephrine (an $\alpha$-Adrenoceptor Agonist, $10 \mu \mathrm{M})(\mathrm{B})$

Papaverine (PPV, $100 \mu \mathrm{M}$ ) was added at the end of the experiment and produced near $100 \%$ relaxation.
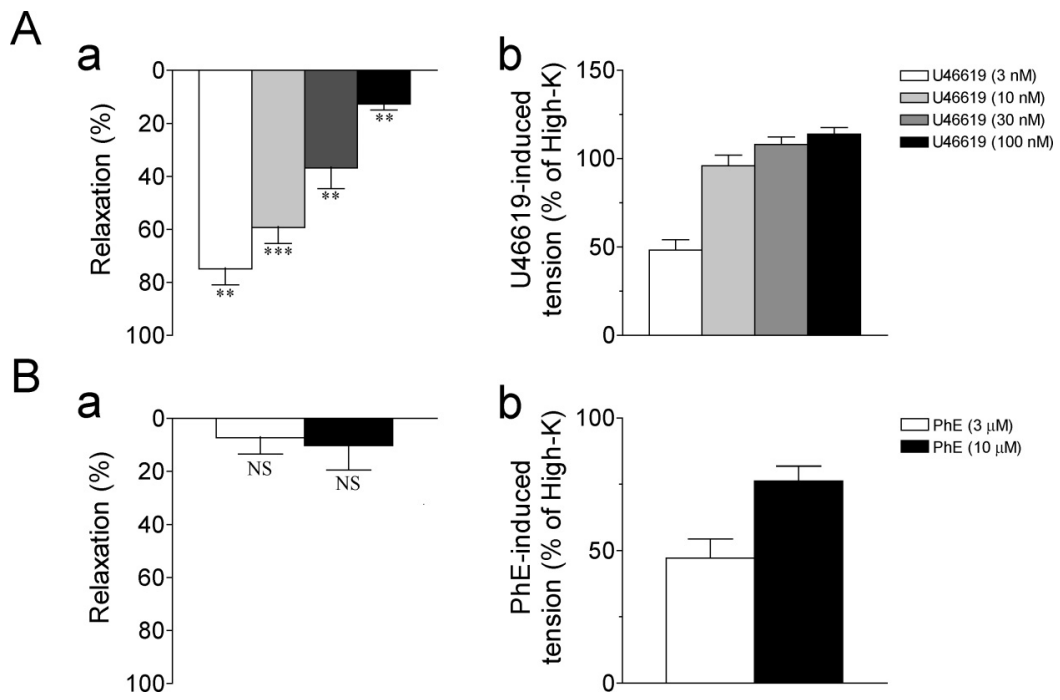

Fig. 2. Summarized Data Which Represent Inhibitory Effects of DHA on the Sustained Contractions of Guinea-Pig Aorta in Responses to U46619 (A) and Phenylephrine (B)

When vascular tension increased by U46619 (3-100 nм) (A) or phenylephrine (3-10 $\mu \mathrm{M})$ (B) reached a steady-state level, DHA (10 $\mu \mathrm{M})$ was applied to the bath solution as shown in Fig. 1. Relaxant effects of DHA are expressed as percent relaxation by calculating with respect to basal tension (100\% relaxation) and U46619 (3-100 nM) (2Aa) or phenylephrine $(3-10 \mu \mathrm{M})(2 \mathrm{Ba})$ steady-state contractile responses $(0 \%$ relaxation). Contractions of guinea-pig aorta in response to U46619 (3-100 nM) (2Ab) and phenylephrine $(\mathrm{PhE}, 3-10 \mu \mathrm{M})(2 \mathrm{Bb})$ are also shown being normalized with respect to high- $\mathrm{KCl}(80 \mathrm{~mm})$-induced muscle tension obtained at the beginning of experiments. Data are mean \pm S.E.M. for 5 experiments for each. $* * p<0.01$, $* * * p<0.005$, NS: significant or no significant (NS) differences from the tension level before administration of DHA. 


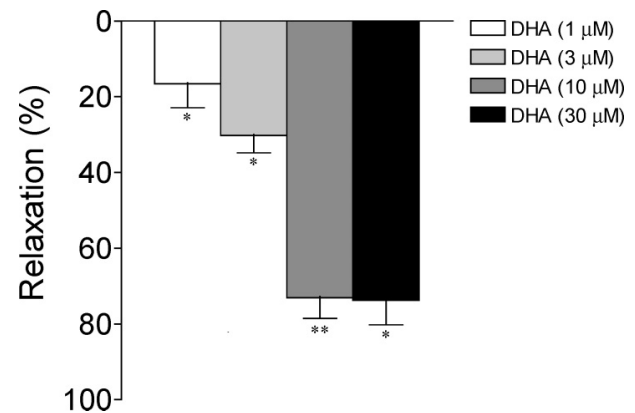

Fig. 3. Concentration-Dependency for the Relaxant Effects of DHA

When the vascular muscle tension increased by U46619 (10 nM) reached a steadystate level, DHA $(1-30 \mu \mathrm{m})$ was applied to the bath solution. Relaxant effects of DHA are expressed as in Fig. 2. Data are mean \pm S.E.M. for $5-6$ experiments for each $* p<0.05, * * p<0.01$ : significant differences from the tension level before administration of DHA.

contraction. In support of this presumption, phospholipid (PL) enrichment with DHA as well as EPA was found to inhibit U46619-induced platelet aggregation and $\left[{ }^{3} \mathrm{H}\right] \mathrm{U} 46619$ specific binding, which were not affected by linoleic acid-enrichment. ${ }^{10)}$ Furthermore, DHA as well as EPA has been shown to prevent vascular smooth muscle cell (SMC) proliferation induced by U46619, which facilitates the formation of atheromatous plaque whereas other fatty acid (arachidonic acid, AA; $\gamma$-linolenic acid, $\gamma$-LNA; oleic acid, OA) exhibited no effects on U46619-induced SMC proliferation. ${ }^{11)}$

Although it may be possible that DHA-induced inhibition of TP receptor-mediated vascular contraction includes mechanisms other than antagonism of this eicosanoid receptor, the present finding is the first indication that DHA strongly diminishes $\mathrm{TXA}_{2}$-induced increase in vascular tone in conduit artery. This study may suggest the effectiveness of consuming DHA, directly or indirectly from dietary precursors, to protect blood vessels including aorta from generating $\mathrm{TXA}_{2}-$ related constrictor responses. Indeed, dietary administration of DHA was demonstrated to reduce significantly $N^{\omega}$-nitroL-arginine-induced, $\mathrm{TXA}_{2}$-like contraction of the isolated aorta from adult spontaneously hypertensive rats with established hypertension. ${ }^{12)}$

Acknowledgements This study was supported in part by the Nestle Foundation (Y.T.).

\section{REFERENCES}

1) Hirafuji M., Machida T., Hamaue N., Minami M., J. Pharmacol. Sci., 92, 308-316 (2003).

2) Wijendran V., Hayes K. C., Annu. Rev. Nutr., 24, 597-615 (2004).

3) Engler M. B., Karanian J. W., Salem N. J., Eur. J. Pharmacol., 185, 223-226 (1990).

4) Engler M. B., Eur. J. Pharmacol., 215, 325-328 (1992).

5) Engler M. B., Cardiovasc. Drugs Ther., 6, 605-610 (1992).

6) Engler M. B., Engler M. M., Browne A., Sun Y. P., Sievers R., Br. J. Pharmacol., 131, 1793-1799 (2000).

7) Engler M. B., Engler M. M., Biol. Res. Nurs., 2, 85-95 (2000).

8) Otsuka K., Tanaka H., Horinouchi T., Koike K., Shigenobu K., Tanaka Y., J. Smooth Muscle Res., 38, 117-129 (2002).

9) Yamaki F., Kaga M., Horinouchi T., Tanaka H., Koike K., Shigenobu K., Toro L., Tanaka Y., Naunyn-Schmiedeberg's Arch. Pharmacol., 364, 538-550 (2001).

10) Swann P. G., Parent C. A., Croset M., Fonlupt P., Lagarde M., Venton D. L., Le Breton G. C., J. Biol. Chem., 265, 21692-21697 (1990).

11) Pakala R., Pakala R., Benedict C., Lipids, 34, 915-920 (1999).

12) McLennan P., Howe P., Abeywardena M., Muggli R., Raederstorff D., Mano M., Rayner T., Head R., Eur. J. Pharmacol., 300, 83-89 (1996). 